\title{
Análise tafonômica de concentrações bioclásticas geradas em modelagem física de um sistema de águas rasas dominado por ondas
}

\author{
Cristiano FICK ${ }^{1,2}$, Elírio Ernestino TOLDO Jr. ${ }^{3}$ \& Eduardo PUHL ${ }^{2}$ \\ 1 Programa de Pós-graduação em Geociências, Instituto de Geociências, Universidade Federal do Rio \\ Grande do Sul. Av. Bento Gonçalves, 9500, CEP 91.540-000, Porto Alegre, RS, Brasil (cristiano.fick@ufrgs.br) \\ 2 Núcleo de Estudos em Correntes de Densidade (NECOD), Instituto de Pesquisas Hidráulicas, Universidade \\ Federal do Rio Grande do Sul. Av. Bento Gonçalves, 9500, CEP 91.501-970, Porto Alegre, RS, Brasil \\ (eduardo.puhl@ufrgs.br) \\ ${ }^{3}$ Centro de Estudos de Geologia Costeira e Oceânica, Instituto de Geociências, Universidade Federal do \\ Rio Grande do Sul. Av. Bento Gonçalves, 9500, CEP 91.540-000, Porto Alegre, RS, Brasil (toldo@ufrgs.br)
}

\begin{abstract}
Resumo. Este estudo procurou detalhar os efeitos deposicionais das dinâmicas de concentração de conchas (retrabalhamento mecânico, winnowing e bypass dinâmico) governadas pelas ondulações. Parâmetros tafonômicos, incluindo orientação e posicionamento das conchas, empacotamento e o conteúdo percentual de matriz (em peso), foram analisados a partir de amostras rígidas e inconsolidadas dos depósitos modelados, bem como pelo imageamento do modelo físico. As orientações topo-base das conchas foram predominantemente concordantes em todo perfil simulado ( $>70 \%)$, porém com um percentual maior de bioclastos oblíquos e verticais nas amostras mais distais do modelo, associadas ao winnowing e ao bypass dinâmico. As orientações em planta mostraram tendências bimodais ou unimodais nos depósitos intermediários do perfil, associadas a dinâmica de retrabalhamento mecânico (na rebentação) e winnowing, e polimodais nas amostragens mais proximais e distais, associados ao retrabalhamento mecânico no espraiamento e bypass dinâmico, respectivamente. 0 posicionamento da concavidade dos bivalves foi majoritariamente para baixo ao longo da seção analisada. $\mathrm{O}$ empacotamento e percentual de matriz foi, respectivamente, denso e mais baixo (30\%) no depósito gerado pelo winnowing, sendo os demais com empacotamento moderado ou disperso. A análise tafonômica empregada em concentrações bioclásticas (coquinas) geradas por modelagem física de ambiente costeiro dominado por onda pode ser utilizada para previsão de determinadas dinâmicas sedimentológicas de acumulação de conchas.
\end{abstract}

Palavras-chave. coquinas, tafonomia experimental, dinâmicas sedimentológicas, modelo físico costeiro

\begin{abstract}
TAPHONOMIC ANALYSIS OF BIOCLASTIC ACCUMULATIONS GENERATED BY PHYSICAL MODELING OF A WAVE-DOMINATED SHALLOW WATER SYSTEM. This analysis aims to detail the depositional effects of the shell concentration dynamics (mechanical reworking, winnowing and dynamic bypass) controlled by the waves. Taphonomic parameters such as the shell orientation and positioning, the packing and the percentage content of matrix (by weight), were analyzed from rigid and inconsolidated samples of the simulated deposits, as well as by the image survey of the physical modeling surface. The top-base orientations of the shells were most concordant $(>70 \%)$ along the entire simulated profile, but with a higher percentage of oblique and vertical bioclasts in samples from more distal sector of the model, associated to the winnowing and dynamic bypass. The fabric orientation showed bimodal and unimodal tendencies at the intermediate deposits of the profile, associated with the dynamics of mechanical reworking (from breaking zone) and winnowing, and polymodal in the more proximal and distal deposits, associated to the mechanical reworking (from swash zone) and dynamic bypass, respectively. The bivalve shells were mostly concave-down in all simulated deposits. The packing and the percentage of matrix were, respectively, dense and lower (30\%) in the deposit generated by the winnowing, being the others with moderate or disperse packing. The taphonomic analysis employed on bioclastic concentrations (coquina) physically modelled as a wave-dominated coastal environment can be used to predict specific sedimentological dynamics of shell accumulation.
\end{abstract}

Keywords. coquinas, experimental taphonomy, sedimentological dynamics, coastal physical model 


\section{Introdução}

Acumulações sedimentológicas de fósseis podem ser descritas em termos de modificação post mortem de partes esqueletais e do seu arcabouço deposicional, com a finalidade de entender o tipo e a intensidade dos processos mecânicos, biológicos e químicos que atuaram sobre os fósseis desde a morte do organismo até sua preservação final. Em relação às acumulações bioclásticas de conchas de moluscos, parâmetros como orientação (em planta e seção), grau de empacotamento, seleção, fragmentação (menica, bioerosão ou incrustação) e abrasão das carapaças são atributos tafonômicos bastante empregados (Kidwell et al., 1986; Kidwell, 1991; Kidwell \& Holland, 1991; Zuschin et al., 2003). A descrição destes parâmetros permite diferenciar fácies tafonômicas (ou tafofácies) dentro de um pacote sedimentar de coquinas - como são genericamente chamadas as acumulações de conchas mecanicamente retrabalhadas (Shäfer, 1972) em ambientes costeiros - de modo a detalhar os agentes de modificação de bioclastos no sedimento, durante a incorporação na rocha e retrabalhamento mecânico dos bioclastos, bem como aprimorar a interpretação paleoambiental.

Exemplos da aplicação de parâmetros tafonômicos em estudos de pacotes de coquinas antigas das bacias sedimentares brasileiras podem ser constatados em diversos estudos, nos quais se destacam Simões \& Kowalewski (1998), que analisaram a Camada de Conchas Ferraz da Formação Corumbataí (Permiano Médio e Superior), Bacia do Paraná; Tavares et al. (2015) e Chinelatto et al. (2018) que estudaram um espesso pacote de coquinas (>50m) da Formação Morro do Chaves (Cretáceo Inferior), Bacia Sergipe-Alagoas; e Muniz (2013), que descreveu testemunhos da sequência de coquinas da Formação Coqueiros (Cretáceo Inferior), Bacia de Campos. Nestes trabalhos, os autores sugerem que coquinas com alto grau de fragmentação, orientação plano-paralela com concavidade para baixo e empacotamento denso das conchas podem ser geradas pela dinâmica de tração/ ressuspensão de sedimentos e winnowing (sensu Kidwell, 1986) intensas, induzidas por ondas e correntes de tempestades em zonas próximas a linha de costa (acima do nível de base das ondas). Por outro lado, acumulações de moluscos não fragmentados, com orientação vertical ou oblíqua e empacotamento moderado ou disperso sugerem menor intensidade de remobilização de bioclastos em zonas costeiras mais profundas (abaixo do nível de base das ondas). Estudos recentes em acumulações bioclásticas modernas (Quaternário) em zonas costeiras do Brasil também utilizam critérios tafonômicos para a interpretação dos processos e condições ambientais de sua formação. Exemplos disso são Fornari et al. (2012), Ritter et al. (2013) e Porto-Barros et al. (2017) que analisaram depósitos holocênicos de conchas na planície costeira do Rio Grande do Sul (Tramandaí), de Santa Catarina (Jaguaruna) e Rio de Janeiro (Região dos Lagos), respectivamente. Já em ambiente marinho plataformal, Erthal \& Ritter (2020) aplicaram o estudo da tafonomia de depósitos bioclásticos recentes ao entendimento estratigráfico da plataforma continental do extremo sul brasileiro.

Tendo em vista a importância e a boa aplicabilidade da análise tafonômica no estudo de acumulações de conchas de moluscos em ambientes costeiros, esta ferramenta se mostra bastante promissora na interpretação de depósitos bioclásticos gerados em modelagem física, como apresentado em Fick et al. (2018). No referido trabalho, os autores simularam, em escala reduzida, um perfil longitudinal de águas rasas utilizando um canal de laboratório, sob a ação de um gerador de ondas em um fundo sedimentar arenoso e com aporte gradual de conchas carbonáticas. Entre os resultados, as simulações demostraram que as dinâmicas de concentração de conchas sedimentológicas (sensu Kidwell, 1986) são controladas, em um ambiente dominado por ondas, pelos processos de transformação do fluxo oscilatório ao se aproximar da costa (empolamento, quebra e espraiamento), havendo, portanto, zonas de domínio de determinadas dinâmicas (retrabalhamento mecânico, winnowing, by-pass dinâmico) ao longo do perfil costeiro. Além disto, foram gerados diferentes tipos de acumulações de bioclastos, sendo cada um atribuído a uma das dinâmicas observadas. No entanto, em Fick et al. 
(2018), os depósitos de coquinas simulados não foram detalhados quantitativamente quanto aos parâmetros tafonômicos, principalmente quanto à orientação das conchas em seção base-topo.

Com a finalidade de aprofundar a descrição do depósito simulado por (Fick et al. 2018), este trabalho tem por objetivo analisar essas acumulações bioclásticas aplicando parâmetros tafonômicos pertinentes, baseados em Kidwell et al. (1986) e Kidwell (1991). As análises foram conduzidas a partir da amostragem dos sedimentos, tanto indeformadas (resinadas) quanto inconsolidadas, imagens da superfície e em seção das amostras indeformadas. A partir desta descrição mais detalhada, uma comparação mais robusta com fácies de coquinas do registro sedimentar foi realizada.

\section{Materiais e métodos}

\subsection{Síntese do modelo físico}

Nesta seção, uma síntese dos experimentos realizados e resultados obtidos em Fick et al. (2018) é apresentada para uma melhor contextualização do problema investigado pelo presente trabalho. Com o objetivo principal de observar os controles dos processos de transformação da onda - empolamento, quebra e espraiamento - sobre as dinâmicas sedimentológicas de concentração de conchas, experimentos de modelagem física em escala reduzida foram realizados em um canal com dimensões de 40,0 $\mathrm{m}$ de comprimento, 1,0 m de largura e 0,56 m de profundidade (Fig. 1A). As ondulações foram geradas por um gerador de ondas do tipo placa metálica oscilante (articulada no fundo) instalado no interior de uma das extremidades do canal. Os sedimentos utilizados na construção do perfil costeiro foram areia fina quartzosa $\left(D_{50}=0,125 \mathrm{~mm}\right)$ e conchas de moluscos das classes bivalvia (Fig 2A e 2B) e gastropoda (Fig 2C e 2D), fragmentadas e inteiras, variando em tamanho de $1,0 \mathrm{~mm}$ a $20,0 \mathrm{~mm}$ $\left(D_{50} \sim 3,0 \mathrm{~mm}\right)$. Tais moluscos foram obtidos de depósitos da planície costeira de Santa Catarina (Jaguaruna), onde a atividade mineradora explora este material para fins comerciais, ou seja, a escolha das espécies utilizadas nos experimentos foi meramente por um fator de disponibilidade e não pelo viés experimentalcientífico. O perfil inicial teve aproximadamente $17 \mathrm{~m}$ de comprimento, com uma inclinação de $1^{\circ}$.

Os cenários de simulação visaram reproduzir um perfil costeiro lacustre baseado em um setor do Lago Tanganyika, sudeste da África, devido este ser considerado um bom análogo aos antigos lagos rifte existente durante a abertura do Gondwana (Thompson et al., 2015), usando a declividade e a altura de onda média deste setor para calibrar o modelo, conferindo uma redução de escala de 1/20. Nestes lagos-rifte, espessos pacotes de coquinas foram depositados, os quais representam importantes reservatórios de hidrocarbonetos nas atuais bacias de Campos e Santos, pertencentes às sequencias do Pré-sal (Bertani \& Carozzi, 1985; Dias et al., 1988; Abrahão \& Warme, 1990; Carvalho et al., 2000; Terra et al., 2010; Muniz, 2013). Além disto, os experimentos reproduziram alternadas condições de onda, ciclos de tempo bom (menor altura e período de onda) e de tempestade (maior altura e período de onda), com um aporte de conchas constante (modelo R-sediment, sensu Kidwell, 1986) sobre o fundo arenoso entre cada ciclo. No total, foram realizadas 54 horas de simulações divididas em 18 experimentos que variavam de 2 a $3 \mathrm{~h}$ de duração. 0 perfil costeiro simulado ao final dos experimentos apresentou variadas formas, semelhantes às de perfis praiais, como berma, banco, cava, banco de tempestade e lençol (Fig. 1B e 1C). Formas de fundo do tipo ripples ocorreram ao longo de todo perfil sedimentar, sendo mais simétricas em zonas com maior profundidade e afastadas da linha de costa, e assimétricas em zonas rasas próximas à linha de costa.

Quanto às dinâmicas sedimentológicas de concentração de conchas verificou-se um zoneamento dos seus domínios ao longo do perfil (Fig 3A). A dinâmica de retrabalhamento mecânico: remobilização de areia e rolamento, saltação e tração dos bioclastos, ocorreu de forma dominante dentro da zona de quebra e espraiamento da onda, tanto nos experimentos de tempo-bom (curta extensão do perfil), quanto nos de tempestade (ampla extensão do perfil). A dinâmica de winnowing: remoção e suspensão da 


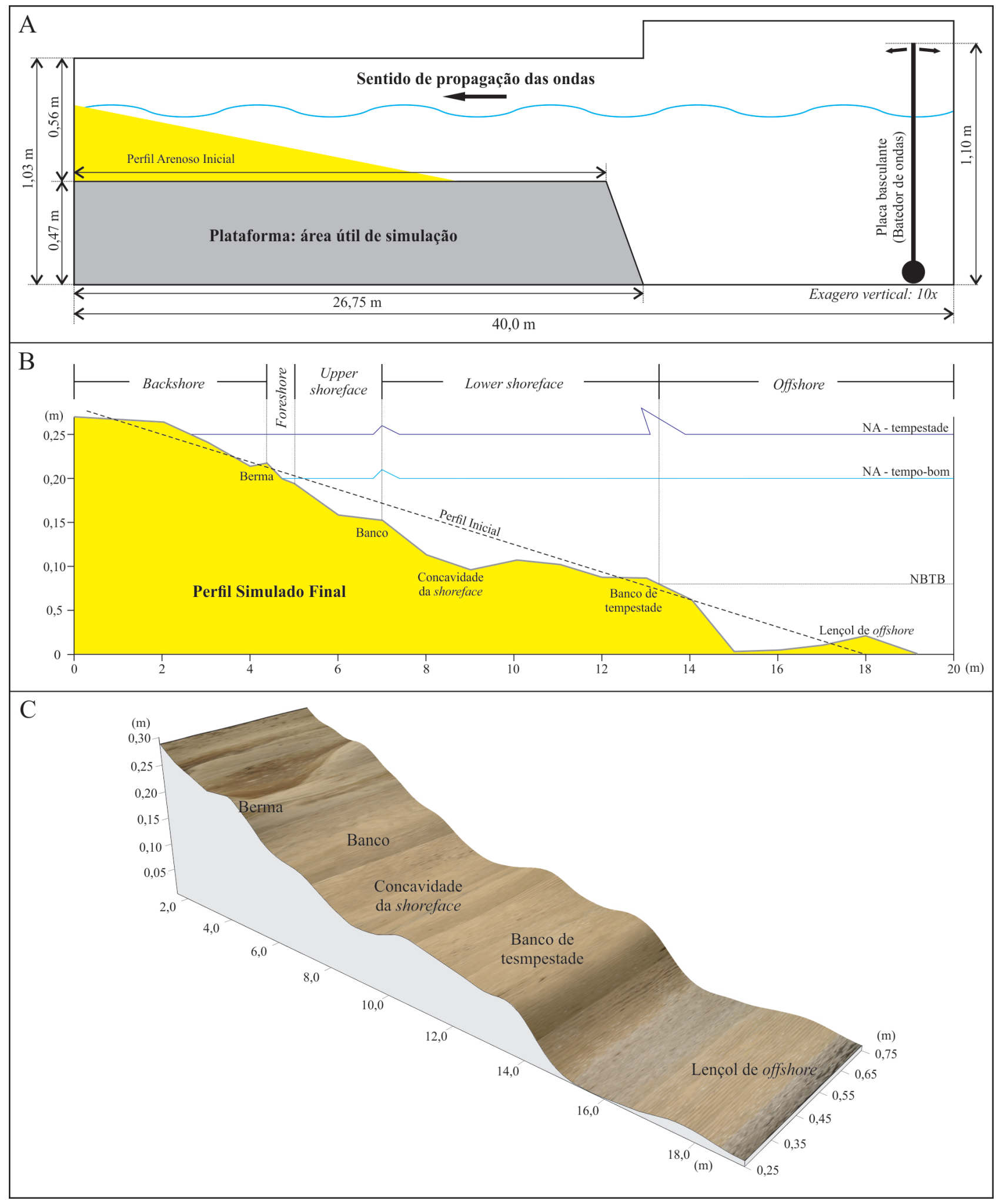

Figura 1. Características do modelo físico. A) Geometria longitudinal do canal utilizado na modelagem física e posição do perfil arenoso inicial (modificado de Fick et al., 2018); B) Morfologia final do perfil costeiro simulado (modificado de Fick et al., 2018); C) Modelo 3D do perfil costeiro simulado mostrando, em detalhe, sua morfologia e feições características. Figure 1. Physical model characteristics. A) Longitudinal geometry of the flume used in the physical modeling and the location of the initial sandy profile (modified from Fick et al., 2018); B) Final morphology of the simulated coastal profile (modified from Fick et al., 2018); C) 3D model of the simulated coastal profile showing, in detail, its morphology and characteristic features. 

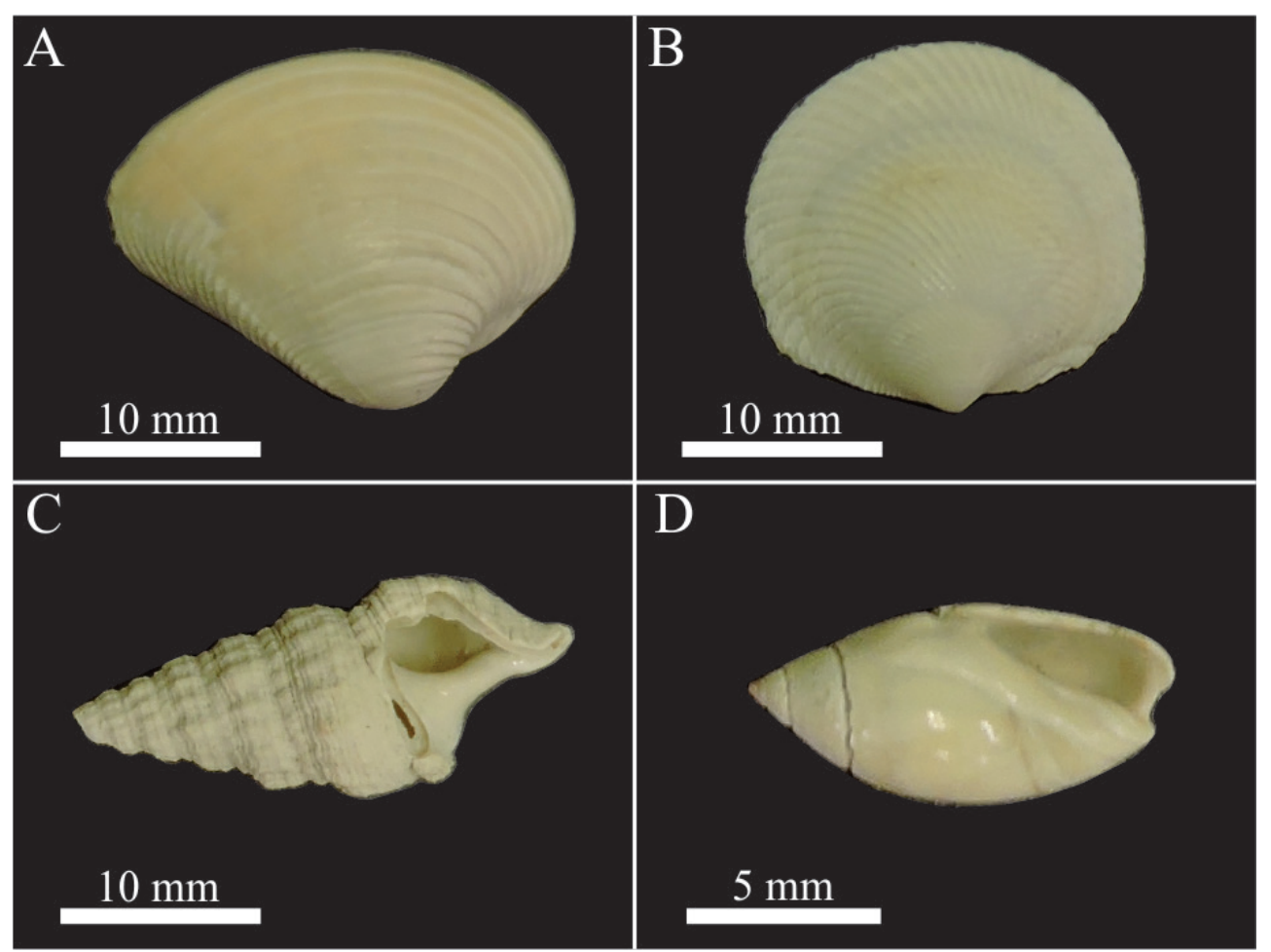

Figura 2. Espécies de moluscos mais abundantes usadas na modelagem física. A) Anomalocardia brasiliana (Gmelin, 1791); B) Diplodonta punctata (Say, 1822); C) Cerithium eburneum (Bruguière, 1792); D) Olivella sp.

Figure 2. Main mollusc species used in the physical modeling. A) Anomalocardia brasiliana (Gmelin, 1791); B) Diplodonta punctata (Say, 1822); C) Cerithium eburneum (Bruguière, 1792); D) Olivella sp.

areia e movimentação incipiente dos bioclastos, prevaleceu na zona de empolamento, logo atrás do primeiro ponto de quebra da onda, durante os experimentos de tempestade. Outra dinâmica observada foi o bypass dinâmico: migração da areia sob a forma de ripples sobre os bioclastos imobilizados, ocorrendo essencialmente na zona de empolamento durante simulações de tempobom e tempestade, sendo neste último caso em porções mais distais.

Quatro tipos de acumulações de conchas foram gerados ao longo do perfil (Fig. 3A), basicamente restritas às zonas de domínio das dinâmicas já descritas, conforme segue.

SA - concentração esparsa de conchas sobre a superfície do perfil, exclusivamente de gastrópodes, não havendo empacotamento. Estas acumulações esparsas alóctones se estenderam da shoreface até a zona de espraiamento da onda, estando sob a ação da dinâmica de retrabalhamento mecânico (Fig. 3B).

MS $_{\text {sh }}$ - concentração matriz-suportada de conchas inteiras de bivalves e gastrópodes e fragmentos, com empacotamento moderado a disperso e espessura máxima de $5,0 \mathrm{~cm}$. $\mathrm{Na}$ sua superfície era comum as conchas ficarem expostas entre as cavas das ripples. Este tipo de depósito remobilizado foi gerado pela ação da dinâmica de retrabalhamento mecânico, estendendo-se do banco de tempestade até concavidade da shoreface (Fig. 3C).

GS - concentração grão-suportada e remobilizada de conchas inteiras de bivalves e gastrópodes (raros) e fragmentos, com empacotamento denso e espessura máxima de 2,0 cm, ocorrendo entre o lençol de offshore e o banco de tempestade na zona de empolamento e, portanto, sob o domínio da dinâmica de winnowing (Fig. 3D).

MS $_{\text {of }}$ - concentração matriz-suportada não-remobilizada de conchas inteiras de bivalves e gastrópodes (raros) e fragmentos, com empacotamento moderado e espessura de até $2,5 \mathrm{~cm}$. Assim como o depósito MSsh, por vezes os bioclastos se apresentavam à superfície entre as cavas das ripples. Sua ocorrência deuse na zona mais distal do perfil, na zona de empolamento, constituindo o corpo deposicional do lençol de offshore. A dinâmica atuante neste depósito foi o bypass dinâmico (Fig. 3E). 


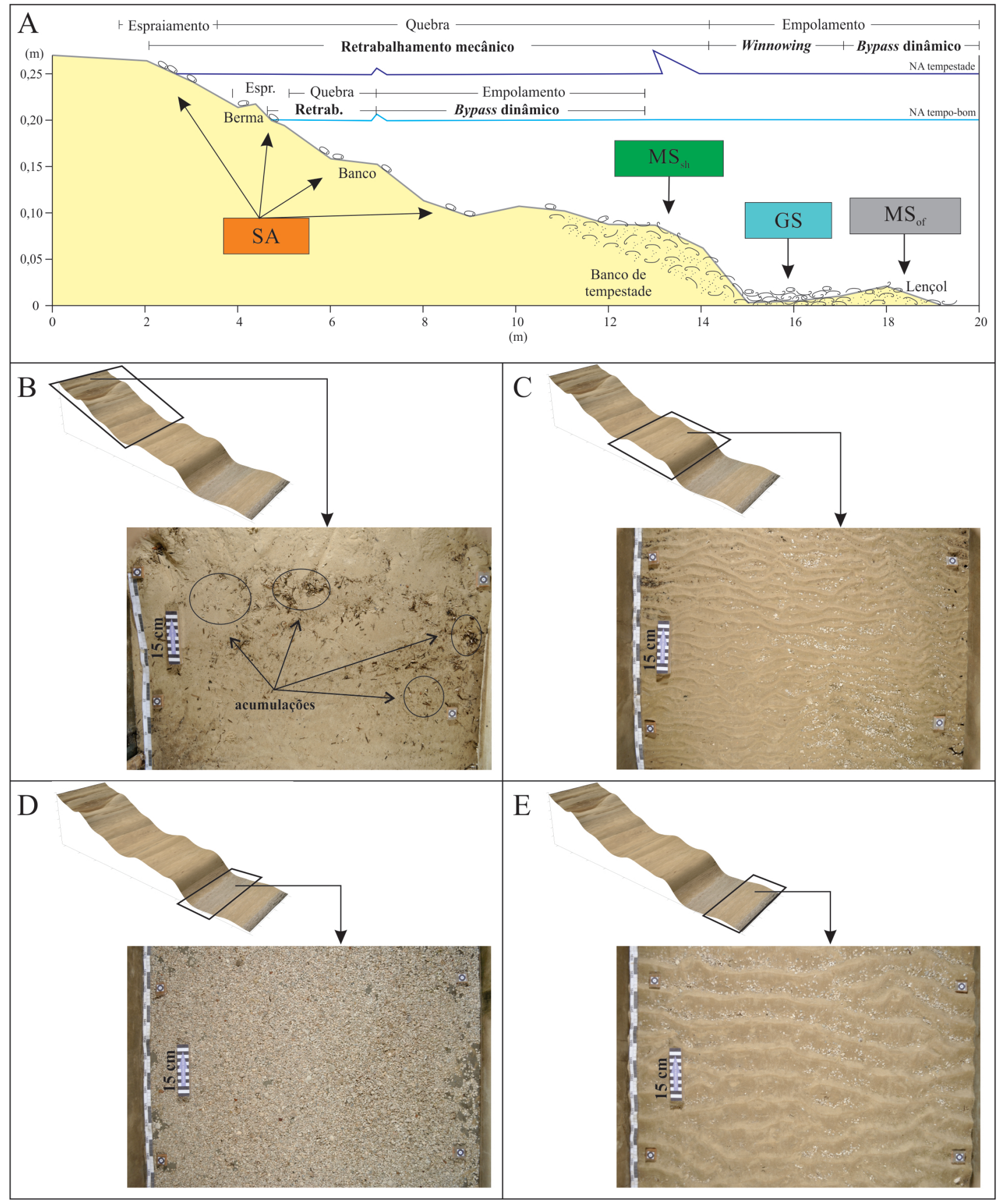

Figura 3. Dinâmicas e tipos de concentração de conchas observadas na modelagem física. A) Zoneamento das dinâmicas sedimentológicas de concentração de conchas e localização dos tipos de concentração de bioclastos gerados ao longo do perfil costeiro simulado (modificado de Fick et al., 2018); B) Imagem aérea da concentração SA; C) Imagem aérea da concentração $\mathrm{MS}_{\text {sh }}$; D) Imagem aérea da concentração GS; E) Imagem aérea da concentração $\mathrm{MS}_{\text {of }}$.

Figure 3. Dynamics and types of shell concentration observed in the physical modeling. A) Zonation of the sedimentological dynamics of shell concentration and the location of the shell concentration types generated along the simulated coastal profile (modified from Fick et al., 2018); B) Top view of the SA concentration; C) Top view of the MS $_{\text {sh }}$ concentration; D) Top view of the GS concentration; E) Top view of the $M S_{\text {of }}$ concentration. 
Cada uma das concentrações geradas no experimento foi devidamente amostrada e fotografada, o que permitiu analisar parâmetros tafonômicos e sedimentológicos, como: o empacotamento, a orientação em planta e em seção das conchas e o percentual de matriz. A partir deste material, o presente trabalho buscou aprimorar algumas análises já apresentadas em Fick et al. (2018) e acrescentar outras inéditas, o que proporcionou reforçar as comparações dos depósitos gerados nas simulações com os do registro sedimentar.

\subsection{Imageamento da superfície do perfil simulado}

Após o fim das simulações, o perfil costeiro modelado foi inteiramente fotografado em detalhe. Com uma câmera digital Nikon D5000 (18-55 mm) acoplada a uma plataforma móvel sobre as paredes do canal, foram obtidas 36 fotografias com boa resolução da superfície do depósito, de modo a cobrir toda a extensão do perfil. Estas fotografias permitiram visualizar detalhadamente os bioclastos e as formas de fundo sobre a superfície do perfil. A partir destas imagens foi realizada a medição da orientação em planta das conchas e quanto ao posicionamento da concavidade dos bivalves: para cima ou para baixo.

\subsection{Levantamento topográfico do perfil simulado}

O levantamento da topografia do depósito foi realizado com um distanciômetro a laser
MD250 ADV (precisão 0,1 mm) acoplado a uma mesa mecanizada que realizava a movimentação controlada do laser sobre a superfície. Esta mesa era posicionada sobre o canal, de modo a cobrir uma área de 1,0 m de comprimento (longitudinal) e 0,50 m de largura (transversal), com os respectivos espaçamentos de aquisição de 1,5 cm e 0,1 cm. No total foram realizados 20 levantamentos (grids) ao longo do perfil ( $20 \mathrm{~m}$ comprimento) de maneira que toda sua superfície fosse levantada. Com o uso do aplicativo Surfer 8.0, todos os grids foram unidos e processados gerando um modelo 3D do perfil simulado. Este levantamento permitiu melhor visualização da morfologia do modelo físico e sua correlação com os tipos de concentrações gerados.

\subsection{Amostras de material inconsolidado}

Amostras de material inconsolidado das acumulações de conchas geradas ao longo do perfil foram coletadas para análise da quantidade relativa de matriz (areia) e bioclastos em peso. No total, oito amostras com massa variando de 0,15 a 0,35 kg de material foram obtidas, nomeadas de Al-1 a Al-8 da mais proximal para a mais distal. Após a coleta, o material foi secado em estufa para remover a umidade e peneirado para separar a areia dos bioclastos. Com o uso de uma balança Marte AS5500C (0,01 gr de precisão) cada componente da amostra foi pesado para posterior cálculo da proporção de bioclastos na amostra. Na tabela 1 constam a localização longitudinal da amostra, o respectivo tipo de concentração a que pertence e os pesos de cada componente.

Tabela 1. Características das amostras inconsolidadas.

Table 1. Unconsolidated sample characteristics.

\begin{tabular}{lccccc}
\hline Amostra & $\begin{array}{c}\text { Tipo de } \\
\text { acumulação }\end{array}$ & $\begin{array}{c}\text { Localização } \\
\text { longitudinal } \\
\text { no perfil }(\mathrm{m})\end{array}$ & $\begin{array}{c}\text { Massa total } \\
(\mathrm{kg})\end{array}$ & $\begin{array}{c}\text { Massa de } \\
\text { areia }(\mathrm{kg})\end{array}$ & $\begin{array}{c}\text { Massa de } \\
\text { conchas (kg) }\end{array}$ \\
\hline AI-1 & $\mathrm{MS}_{\mathrm{sh}}$ & 12,00 & 0,35 & 0,31 & 0,04 \\
$\mathrm{AI}-2$ & $\mathrm{MS}_{\mathrm{sh}}$ & 13,60 & 0,30 & 0,28 & 0,02 \\
$\mathrm{AI}-3$ & $\mathrm{MS}_{\mathrm{sh}}$ & 14,80 & 0,18 & 0,12 & 0,06 \\
$\mathrm{AI}-4$ & $\mathrm{GS}$ & 15,20 & 0,16 & 0,05 & 0,11 \\
$\mathrm{AI}-5$ & $\mathrm{GS}$ & 16,00 & 0,18 & 0,05 & 0,13 \\
$\mathrm{AI}-6$ & $\mathrm{GS}$ & 16,60 & 0,34 & 0,17 & 0,17 \\
$\mathrm{AI}-7$ & $\mathrm{MS}_{\mathrm{of}}$ & 17,20 & 0,20 & 0,18 & 0,02 \\
$\mathrm{AI}-8$ & $\mathrm{MS}_{\mathrm{of}}$ & 18,00 & 0,22 & 0,16 & 0,06 \\
\hline
\end{tabular}




\subsection{Amostras rígidas}

Amostras indeformadas dos depósitos foram coletadas com aplicação da técnica de testemunhagem utilizada por Fick et al. (2017) em um modelo físico deltaico. A resina utilizada para simular a consolidação era constituída por três componentes: Aradur 53-S, Araldite LY 1316 BR e Araldite DY 023, com proporção de 35\%, $59 \%$ e $6 \%$, respectivamente. A resina foi aplicada em furos e fendas feitos no modelo físico, e espalhada sobre áreas da sua superfície (Fig. 4A), sendo extraídas, após a secagem (24 h), seis amostras rígidas das acumulações de conchas (Fig. 4B - 4G), que foram nomeadas de AR-1 a AR-6 da mais proximal a mais distal. Estas amostras permitiram observar e analisar com detalhe as características internas dos depósitos de coquinas simulados, como: a orientação em seção das conchas e o grau de empacotamento. As amostras também foram serradas ao meio ou em diversas seções para ampliar a coleta de medições e observação.

\subsection{Análise dos parâmetros tafonômicos}

Os parâmetros tafonômicos analisados nas concentrações de conchas foram: orientação topo-base (seção) e em planta, grau de empacotamento e posicionamento da concavidade dos bivalves, e quantificação da proporção de conchas e matriz arenosa (em peso). A orientação topo-base das conchas (inteiras e fragmentadas) foi caracterizada em função da sua inclinação em relação à base da camada (Fig. 5A), sendo classificadas em concordante $\left(0^{\circ}\right.$ a $\left.30^{\circ}\right)$, oblíqua $\left(30^{\circ}\right.$ a $\left.60^{\circ}\right)$ e vertical $\left(60^{\circ}\right.$ a $\left.90^{\circ}\right)$, conforme Kidwell et al. (1986) e Kidwell (1991). Através de imagens das seções das amostras rígidas, as orientações dos bioclastos foram medidas por meio do aplicativo Corel Draw X6 com organização dos dados percentuais para interpretação estatística. A orientação em planta das conchas (somente inteiras) foi medida pelo azimute do umbo, para os bivalves, e da abertura, para os gastrópodes, tomando como norte o rumo da costa (onshore). A partir das fotografias obtidas no imageamento da superfície do modelo físico, essas direções foram medidas utilizando o aplicativo Corel Draw X6 e sua análise foi demonstrada por diagramas de roseta. A classificação da orientação em planta foi feita segundo a moda dos diagramas, sendo classificada em unimodal, bimodal ou polimodal (Fig. 5B), conforme proposto por Kidwell et al. (1986). Também se utilizou as imagens de superfície para caracterizar o posicionamento da concavidade dos bivalves. O grau de empacotamento foi caracterizado através de uma estimativa visual de imagens (Fig. 5C), podendo ser denso (a maioria dos bioclastos se tocam), moderado (bioclastos por vezes se tocam) ou disperso (bioclastos nunca se tocam), conforme Chinelatto et al. (2018). A proporção de bioclastos e matriz arenosa foi obtida por meio das amostras de material inconsolidado, como já foi descrito na subseção 3.3. Os parâmetros fragmentação e abrasão não foram levantados pois grande parte do material bioclásticos usado nas simulações já era fragmentado ( 90\%) e apresentava intensa abrasão.

\section{Resultados}

Os resultados da análise tafonômica feita nas concentrações de conchas do perfil costeiro simulado foram descritos separadamente para cada tipo de concentração caracterizada por Fick et al. (2018): SA, MS $_{\text {sh' }^{\prime}}$ GS e MS $_{\text {of }}$ Gráficos, diagramas e imagens foram usados para apresentar os dados dos parâmetros orientação em seção das conchas (Fig. 6), orientação em planta e posição da concavidade dos bivalves (Fig. 7), grau de empacotamento (Fig. 8) e conteúdo de matriz / bioclastos (Fig. 9).

\subsection{Concentração SA}

A concentração de conchas SA (sparse accumulation) foi analisada parcialmente, sendo apenas quantificada quanto a orientação em planta de seus bioclastos, pois tratava-se de pequenas acumulações de conchas inteiras, exclusivamente de gastrópodes, espalhadas sobre a superfície da zona mais proximal do perfil simulado (Fick et al., 2018). Como não houve empilhamento de bioclastos, não gerando uma camada, os demais parâmetros tafonômicos 

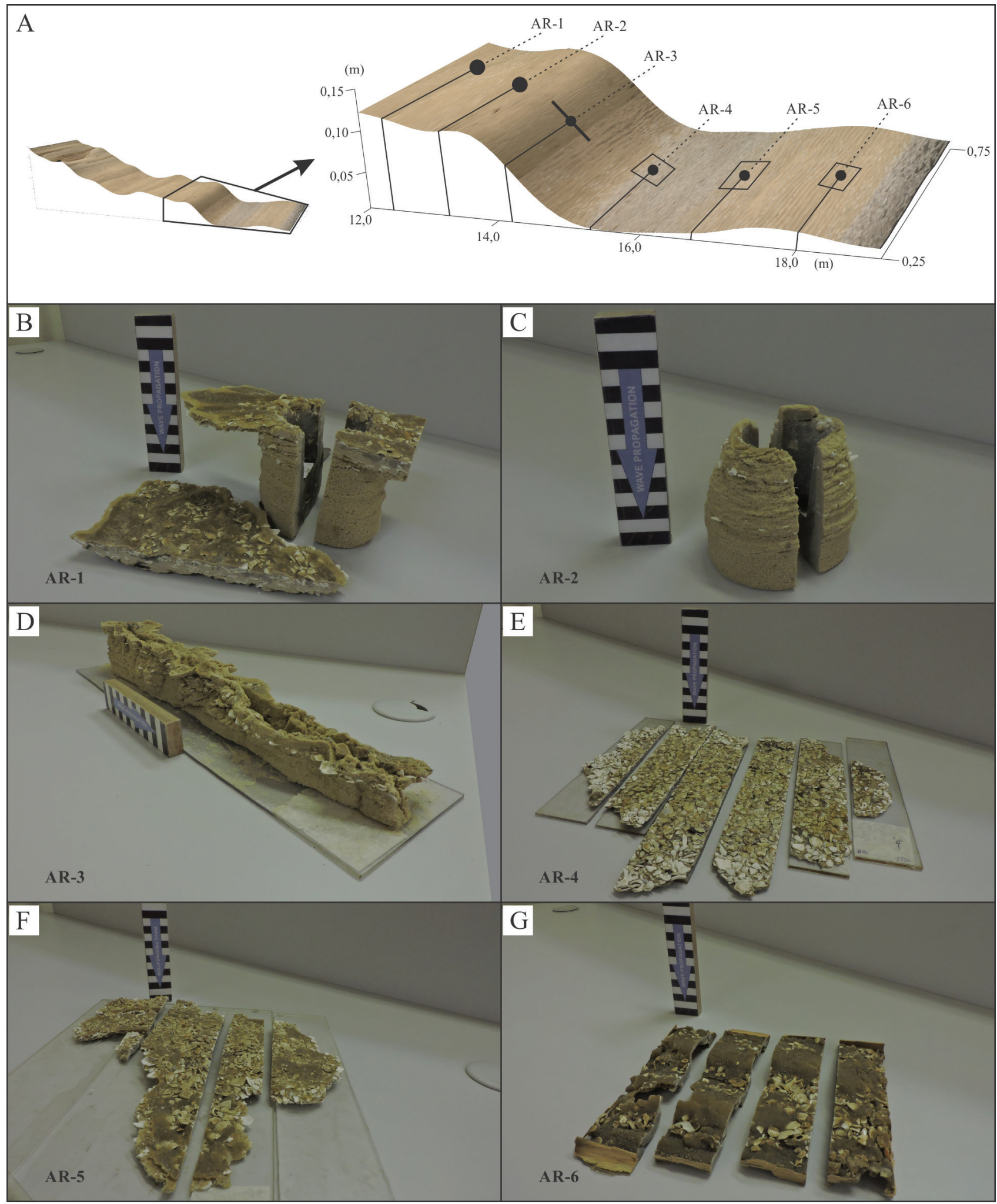

Figura 4. Localização e fotografias das amostras rígidas. A) Modelo 3D do perfil costeiro simulado com a localização das amostras rígidas; B) Amostra AR-1 (12,3 m) - concentração MS ${ }_{\text {sh }}$ C) Amostra AR-2 (13,2 m) - concentração MS sh' D) Amostra AR-3 (14,15 m) - concentração MS ; E) Amostra AR-4 (15,3 m) - concentração GS; F) Amostra AR-5 (16,7 m) - concentração GS; G) Amostra AR-6 (18,0 m) - concentração MS ${ }_{\text {of }}$.

Figure 4. Location and photos of the rigid samples. A) 3D model of the simulated coastal profile with the rigid samples

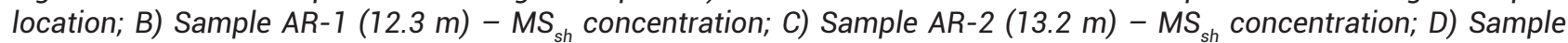
AR-3 (14.15 m) - MSsh concentration; E) Sample AR-4 (15.3 m) - GS concentration; F) Sample AR-5 (16.7 m) - GS concentration; $\mathrm{G})$ Sample AR-6 (18.0 m) - MS of concentration. 


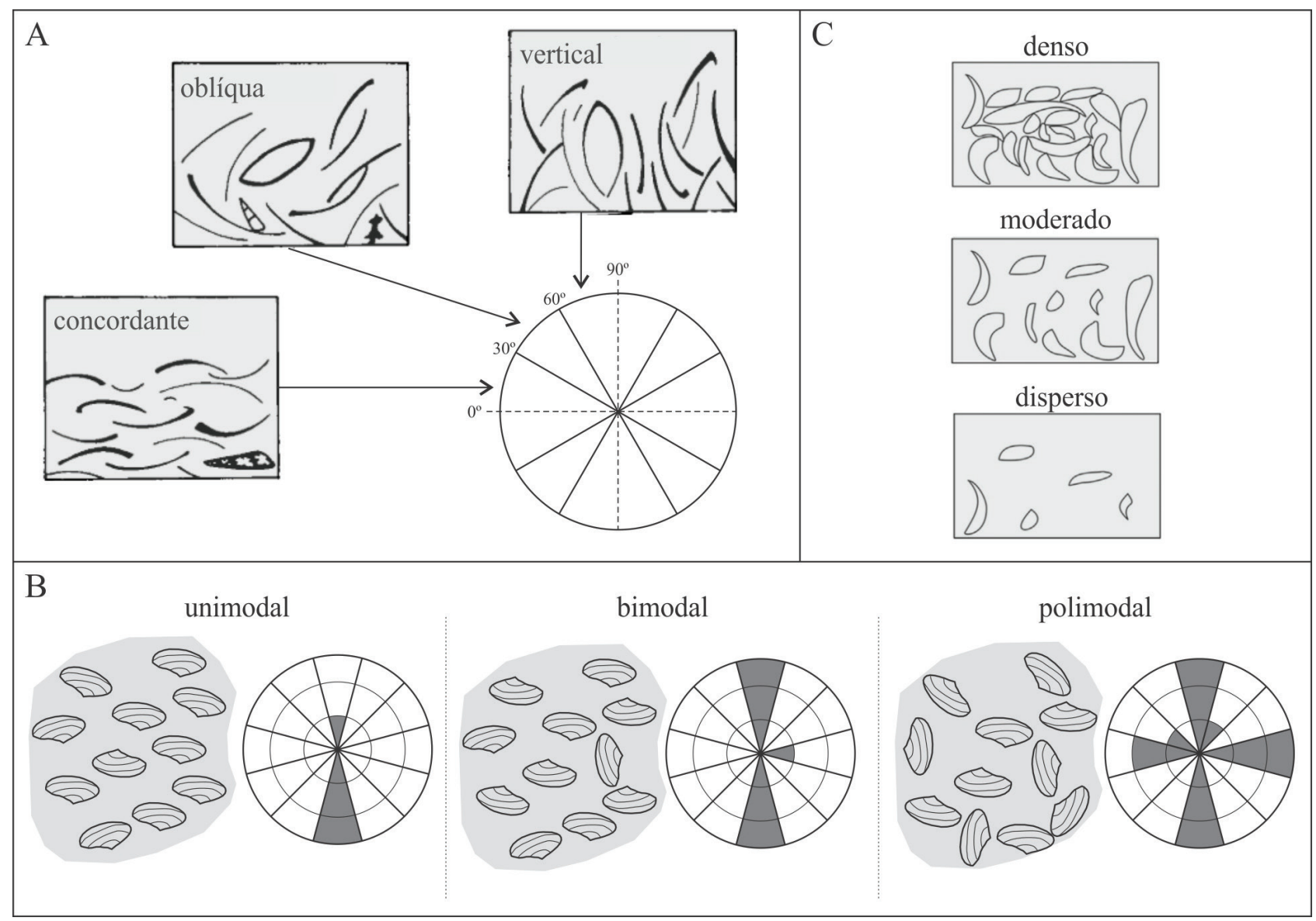

Figura 5, Caracterização dos parâmetros tafonômicos analisados. A) Orientação topo-base (seção) das conchas conforme Kidwell et al. (1986) e Kidwell (1991); B) Orientação em planta das conchas conforme Kidwell et al. (1986) e Kidwell (1991); C) Grau de empacotamento conforme Chinelatto et al. (2018).

Figure 5. Characterization of the taphonomic parameters. A) Top-base orientation (cross section) of shells according Kidwell et al. (1986) and Kidwell (1991); B) Plan-view orientation of shells according Kidwell et al. (1986) and Kidwell (1991); C) Packing of the shell concentration according Chinelatto et al. (2018).

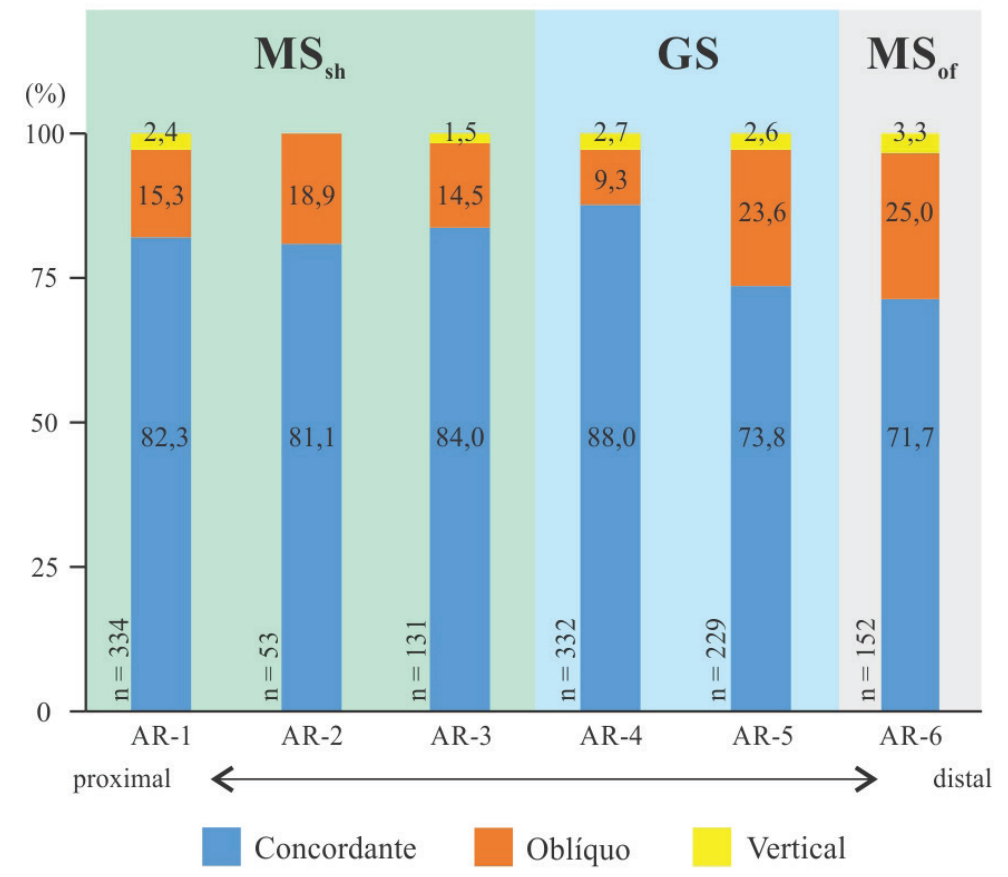

Figura 6. Gráfico da orientação topo-base das conchas relativo às amostras rígidas (AR-1 a AR-6). Figure 6. Graph of the shell top-base orientation related to the rigid samples (AR-1 to AR-6). 


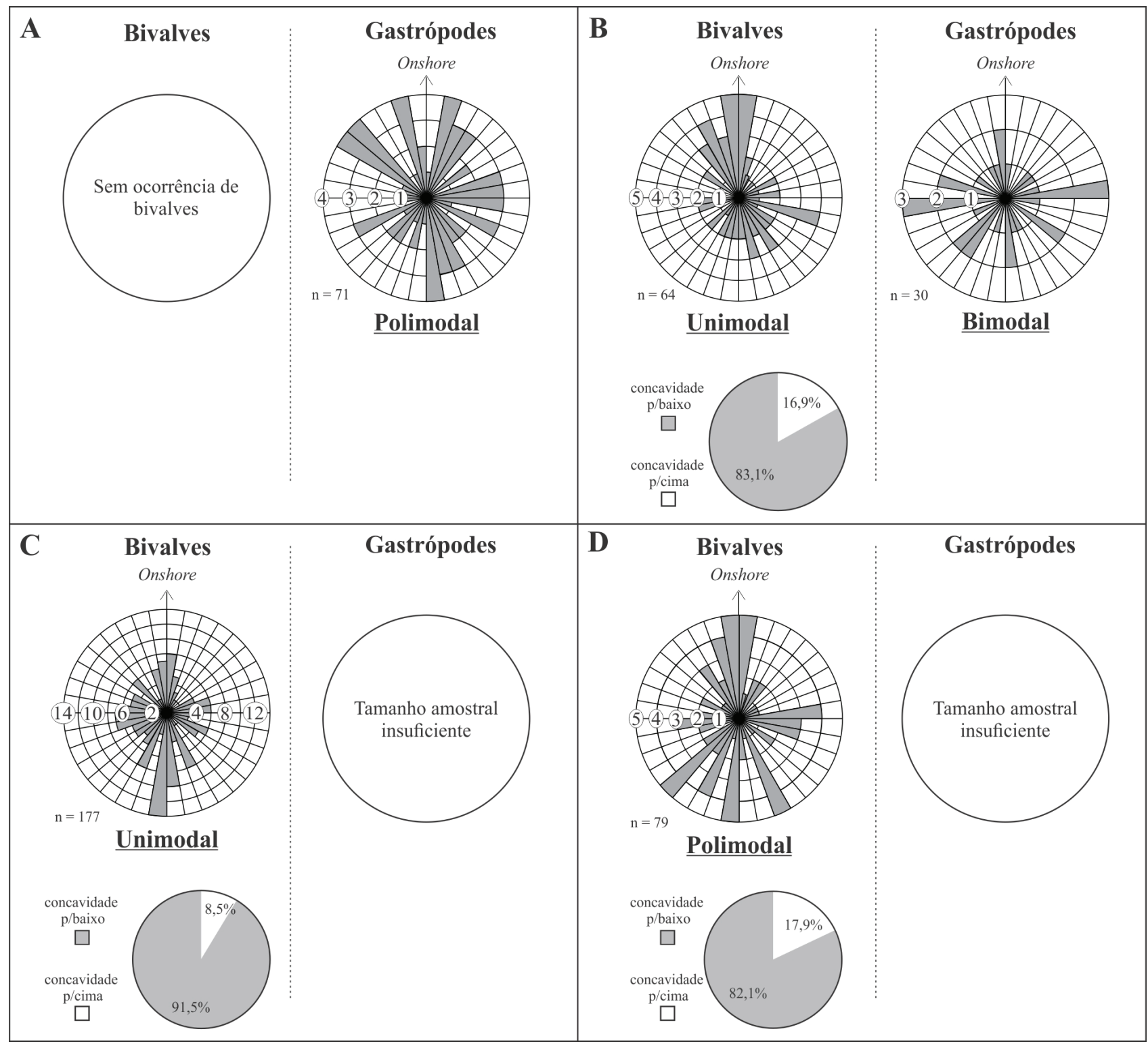

Figura 7. Diagramas de roseta da orientação em planta dos bivalves (umbo) e gastrópodes (abertura) inteiros e gráficos da posição da concavidade dos bivalves. A) Concentração SA; B) Concentração $\mathrm{MS}_{\text {sh }}$; C) Concentração GS; D) Concentração $\mathrm{MS}_{\text {of }}$.

Figure 7. Rose diagrams of the plan-view orientation of whole bivalves (umbo) and gastropods (aperture) and graphs of the bivalve concavity positions. A) SA concentration; B) $M S_{s h}$ concentration; C) GS concentration; D) $M S_{\text {of }}$ concentration.

não foram analisados. Entretanto, sua orientação em planta foi medida e caracterizada como polimodal (Fig. 7A), com um certo direcionamento preferencial perpendicular (N-S) à linha de costa.

\subsection{Concentração $M S_{s h}$}

A concentração de conchas $\mathrm{MS}_{\text {sh }}$ (matrix-supported from shoreface) apresentou medidas de orientação topo-base similares nas suas três amostras rígidas (Fig. 6). As conchas estavam majoritariamente orientadas de maneira concordante (>80\%), secundariamente oblíquas (14\% a 19\%), e pouquíssimas vezes verticais (<2,5\%). Quanto a orientação em planta, os bivalves tiveram um comportamento unimodal (Fig. 7B), com seus umbos apontando preferencialmente para a costa $(\mathrm{N})$, enquanto os gastrópodes apresentavam comportamento bimodal, com a abertura orientada em sentidos opostos para os quadrantes E-W, paralelamente a linha de costa. Os bivalves apresentavam concavidades preferencialmente para baixo (concave-down), em mais de 83\% das ocorrências, enquanto a concavidade para cima (concaveup) ocorreu, aproximadamente, em 17\% desses indivíduos (Fig. 7B). O grau de empacotamento foi moderado a disperso, sendo moderado, 

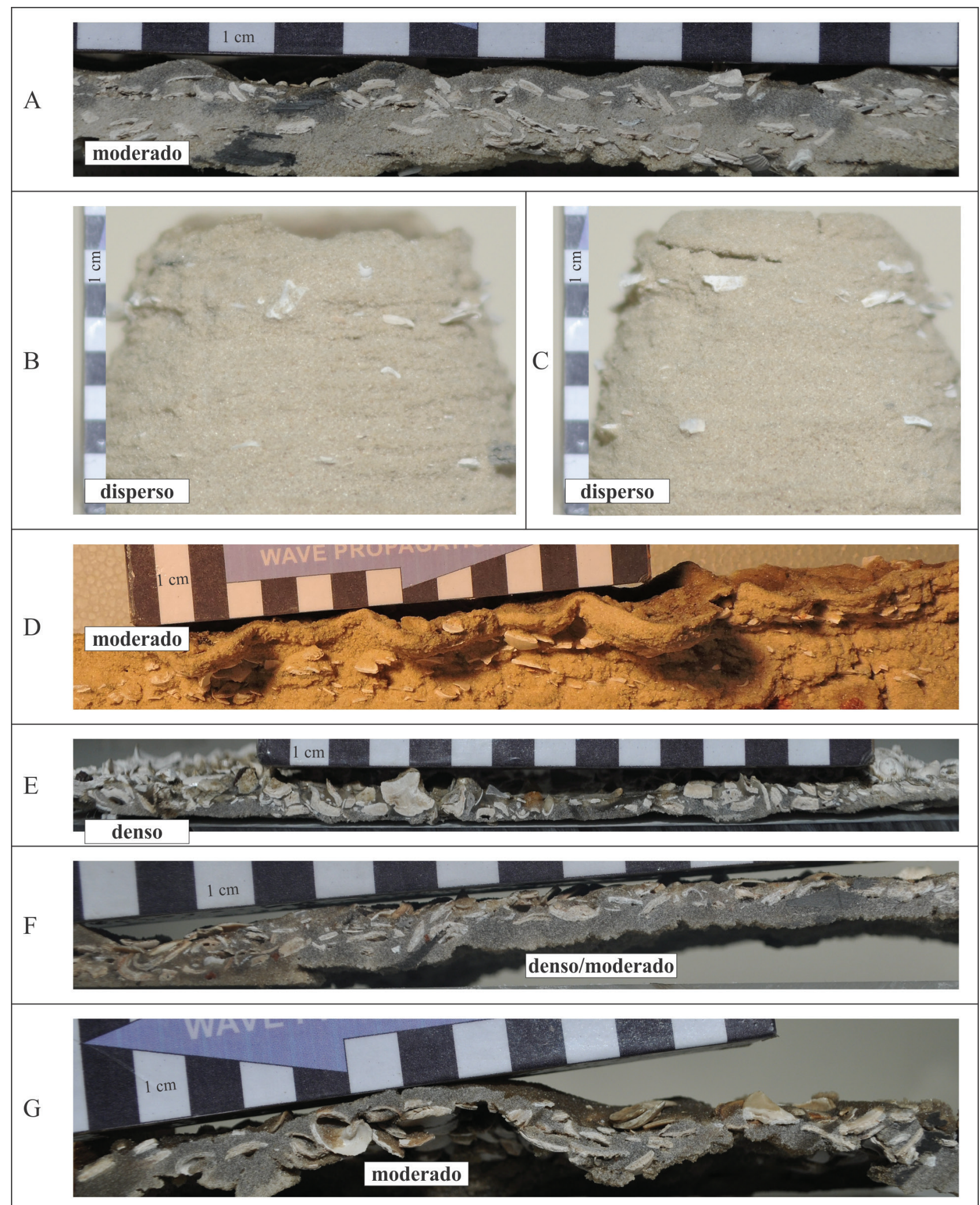

Figura 8. Caracterização do grau de empacotamento nas seções das amostras rígidas. A) Amostra AR-1 (concentração $\mathrm{MS}_{\text {sh }}$ ); B) Amostra AR-2 (concentração MS $\mathrm{Sh}_{\mathrm{sh}}$ ) C) Amostra AR-2 (concentração MS sh); D) Amostra AR-3 (concentração $\mathrm{MS}_{\text {sh }}$ ); E) Amostra AR-4 (concentração GS); F) Amostra AR-5 (concentração GS); G) Amostra AR-6 (concentração MS ${ }_{\mathrm{of}}$ ). Figure 8. Packing characterization on the rigid sample sections. A) Sample AR-1 (MSsh concentration); B) Sample AR-2 $\left(M S_{s h}\right.$ concentration); C) Sample AR-2 (MS ${ }_{s h}$ concentration); D) Sample AR-3 ( $M S_{\text {sh }}$ concentration); E) Sample AR-4 (GS concentration); F) Sample AR-5 (GS concentration); G) Sample AR-6 (MS ${ }_{\text {of }}$ concentration). 


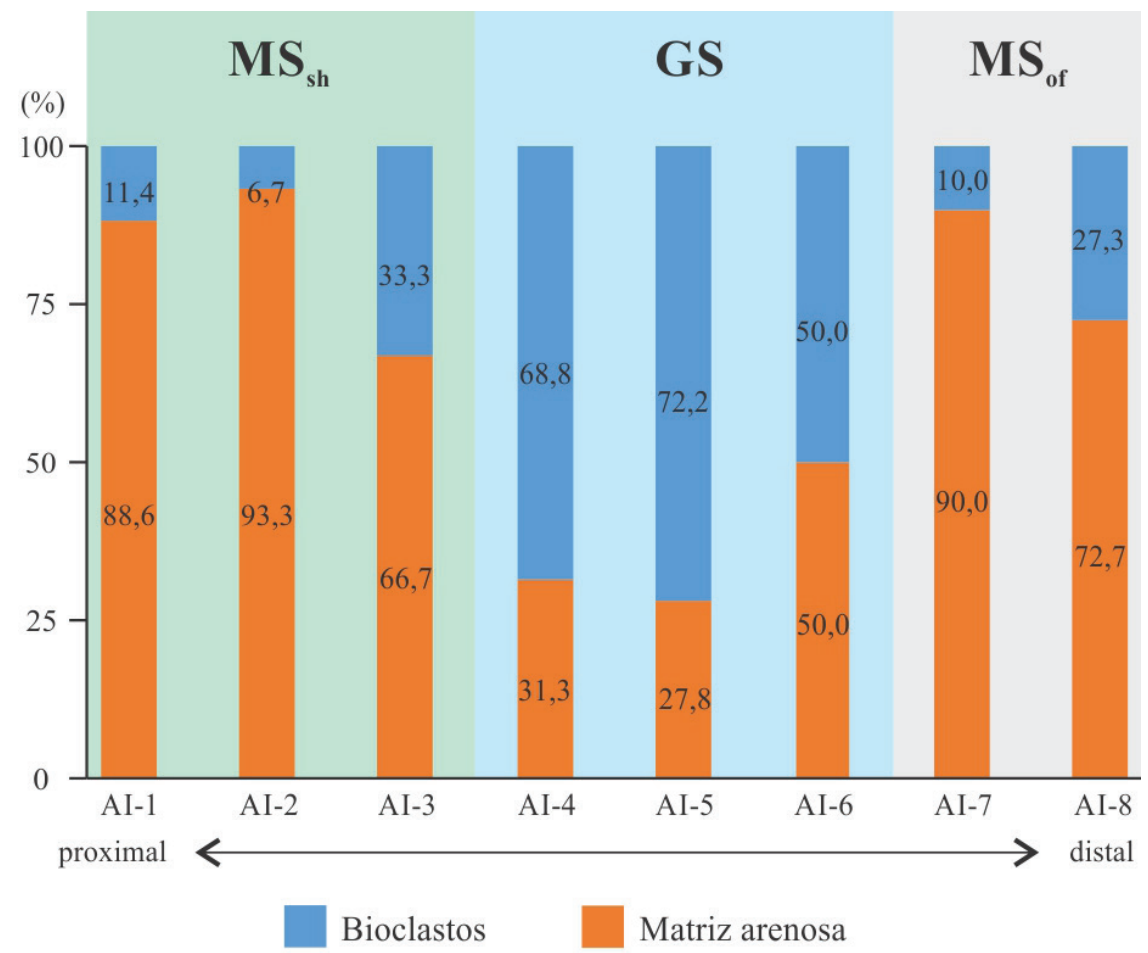

Figura 9. Proporção de matriz e bioclastos das amostras inconsolidadas (Al-1 to Al-8).

Figure 9. Matrix and bioclasts ratio of the unconsolidated samples (Al-1 to Al-8).

em duas das amostras rígidas (Fig. 8A e 8D), e disperso, em uma delas (Fig. 8B e 8D). As três amostras de material inconsolidado indicaram dominância de matriz arenosa sobre a proporção de bioclastos ( $>50 \%$, Fig. 9). No entanto, as duas amostras mais proximais (Al-1 e Al-2) tiveram aproximadamente $90 \%$ de matriz, enquanto a amostra mais distal (Al-3) apresentou percentual de pouco menos de $70 \%$, o que caracteriza uma diminuição na quantidade de matriz desta concentração na direção offshore.

\subsection{Concentração GS}

A concentração de conchas GS (grainsupported) teve orientação topo-base dos bioclastospreferencialmenteconcordante(>70\%), porém com consideráveis diferenças dos valores entre suas duas amostras rígidas analisadas (Fig. 6). Da amostra mais proximal (AR-4) para a mais distal (AR-5), houve uma diminuição de aproximadamente 15\% no percentual de conchas concordantes e um aumento das oblíquas, em mesmo percentual. Já as verticais mantiveram praticamente o mesmo valor (<3\%). A orientação em planta dos bivalves teve comportamento unimodal para direção offshore (S), onde 91,5\% dessas conchas ficaram com a concavidade para baixo e 8,5\% para cima (Fig. 7C). Os gastrópodes não foram amostrados suficientemente para uma análise estatística robusta da orientação em planta e foram desconsiderados. O grau de empacotamento foi caracterizado como denso a moderado, sendo denso na amostra mais proximal (Fig. 8E) e denso/moderado na amostra mais distal (Fig. 8F). Por sua vez, o percentual em peso de bioclastos foi maior ou igual ao de matriz em todas amostras inconsolidadas desta concentração, porém, percebeu-se uma variação nos valores (Fig. 9). Nas duas amostras mais proximais (Al-4 e Al-5) o conteúdo de bioclastos foi de aproximadamente $70 \%$, enquanto a amostra mais distal (AI-6) apresentou percentual de bioclastos e matriz igual a 50\%, o que caracteriza um aumento no conteúdo de matriz desta concentração no sentido offshore. 


\subsection{Concentração $M S_{\text {of }}$}

A concentração $\mathrm{MS}_{\text {of }}$ (matrix-supported from offshore) apresentou orientação topobase (Fig. 6) preferencialmente concordante ( 70\%), e em menor proporção oblíqua (25\%) e vertical $(\sim 5 \%)$. Estes valores indicam que de todas as amostras rígidas analisadas, a amostra representante desta concentração (AR-6) foi a que apresentou o maior percentual de conchas oblíquas ou verticais ( 30\%). O comportamento da orientação em planta dos umbos dos bivalves foi polimodal para diversas direções, conferindo um certo grau de aleatoriedade para este atributo (Fig. 7D). Destes bivalves, 82\% ficaram com a concavidade para baixo e 18\% para cima. Assim como ocorreu na concentração GS, o número de indivíduos gastrópodes foi insuficiente para uma análise estatística rigorosa. O grau de empacotamento foi caracterizado como moderado (Fig. 8G). Já o conteúdo em peso de matriz foi mais elevado do que o de bioclastos em ambas as amostras inconsolidadas desta concentração (Fig. 9), sendo 90\% na mais proximal e $73 \%$ na mais distal, o que caracteriza uma diminuição da quantidade relativa de matriz nesta concentração no sentido offshore.

\section{Discussão dos resultados}

Discussões são apresentadas a seguir, relatando o comportamento de cada um dos parâmetros tafonômicos analisados ao longo do perfil costeiro simulado. Além disto, alguns pontos desta análise são comparados com os observados por outros autores em estudos de camadas e pacotes de coquinas do registro antigo e moderno, como na interpretação tafonômica da Formação Morro do Chaves de Chinelatto et al. (2018), onde semelhanças ou diferenças relativas aos comportamentos mostrados pelo modelo físico são discutidas.

A orientação topo-base dos bioclastos mostrou uma tendência de aumentar sua obliquidade ou verticalização no sentido das áreas mais distais do perfil, embora conchas concordantes tenham sido dominantes. Este comportamento é melhor observado nas amostras AR-5 e AR-6 (Fig. 6), que apresentaram cerca de $10 \%$ a mais conchas obliquas ou verticais do que as demais amostras. Ainda, os valores médios de bioclastos verticais ou oblíquos por tipo de concentração de conchas também corroboram com esta tendência, visto que as concentrações $\mathrm{MS}_{\mathrm{sh}^{\prime}}$ GS e $\mathrm{MS}_{\text {of }}$ possuem médias percentuais de 17,54\%, 19,1\% e 28,3\%, respectivamente. Estas observações sugerem que o comportamento da orientação topo-base das conchas está diretamente ligado à dinâmica sedimentológica a que foram submetidas. Bioclastos que sofreram retrabalhamento mecânico $\left(\mathrm{MS}_{\mathrm{sh}}\right)$, dinâmica de mais alta energia (Fick et al., 2018), tenderam a ser menos oblíquos / verticais e mais concordantes do que aqueles que estiveram submetidos ao winnowing (GS), dinâmica de energia intermediária. Por sua vez, as conchas controladas pelo bypass dinâmico $\left(\mathrm{MS}_{\text {of }}\right)$, dinâmica de mais baixa energia, foram menos concordantes e mais obliquas / verticais do que as duas dinâmicas citadas anteriores.

Em zonas de mais intensa ação de ondas e correntes (foreshore - shoreface superior), a orientação topo-base preferencialmente concordante está relacionada ao movimento e transporte das conchas (retrabalhamento mecânico), que partem de sua posição de vida, geralmente vertical, para um posicionamento paralelo a superfície do leito, que é hidrodinamicamente mais estável e equilibrado (Brenchley \& Newall, 1970; Allen, 1984; Futterer, 1982; Kidwell et al., 1986, Kidwell \& Holland, 1991; Fürsish \& Oschmann, 1993; Simões \& Kowalewski, 1998). Desta maneira, embora o cenário de modelagem física de Fick et al. (2018) não tenha reproduzido a condição inicial de vida dos bioclastos (foram espalhados aleatoriamente sobre o fundo), o comportamento relativo da orientação topo-base ao longo do perfil simulado está de acordo com o esperado em sistemas naturais. Além disto, este comportamento reforça a comparação entre os tipos de concentrações de conchas do modelo físico e as tafofácies da Formação Morro do Chaves de Chinelatto et al. (2018). As tafofácies T3, T4, e T5/T6, que foram comparadas respectivamente aos depósitos $\mathrm{MS}_{\text {sh' }}$ GS e $\mathrm{MS}_{\text {of }}$ (Fick et al., 2018), apresentam uma tendência semelhante, onde as orientações topo-base tendem a aumentar sua verticalização para maiores profundidades (Tabela 2).

A orientação em planta das conchas 
Tabela 2. Percentuais da orientação topo-base e posição da concavidade nas tafofácies de Chinelatto et al. (2018).

Table 2. Percentage of the top-base orientation and the concavity position in the taphofacies of Chinelatto et al. (2018).

\begin{tabular}{lccccc}
\hline $\begin{array}{l}\text { Tafofácies de } \\
\text { Chinelatto } \\
\text { et al. }(2018)\end{array}$ & $\begin{array}{c}\text { \% de conchas } \\
\text { concordantes* }\end{array}$ & $\begin{array}{c}\text { \% de conchas } \\
\text { oblíquas e } \\
\text { verticais * }\end{array}$ & $\begin{array}{c}\text { \% Concav. } \\
\text { p/ baixo* }\end{array}$ & $\begin{array}{c}\% \\
\text { Concav. } \\
\text { / cima* }\end{array}$ & $\begin{array}{c}\text { Concentrações } \\
\text { análogas de } \\
\text { Fick et al. } \\
(2018)\end{array}$ \\
\hline T1 & 49,6 & 50,4 & 45,3 & 40,2 & - \\
T2 & 52,2 & 47,8 & 55,7 & 31,8 & - \\
T3 & 47,6 & 52,4 & 55,6 & 30,4 & $\mathrm{MS}_{\text {sh }}$ \\
T4 & 32,0 & 68,0 & 37,3 & 39,9 & $\mathrm{GS}$ \\
T5 & 35,3 & 64,7 & 41,0 & 40,7 & $\mathrm{MS}_{\text {of }}$ \\
T6 & 31,7 & 68,4 & 39,7 & 40,8 & $\mathrm{MS}_{\text {of }}$ \\
\hline
\end{tabular}

* Valores médios das amostras de cada tafofácies.

mostrou uma tendência unimodal, embora em sentidos opostos, para os bivalves nas zonas de domínio do retrabalhamento mecânico (depósito $\mathrm{MS}_{\mathrm{sh}}$ - Fig. 7B) e winnowing (depósito GS - Fig. 7C), dinâmicas que promovem maior movimentação dos bioclastos. Por outro lado, na zona de domínio do bypass dinâmico (depósito $\mathrm{MS}_{\text {of }}$ - Fig. 7D), dinâmica que promove uma movimentação praticamente nula das conchas, a tendência de orientação foi polimodal, ou seja, teve um caráter aleatório. Esses comportamentos indicam que os bioclastos que sofrem atuação mais intensa de um agente hidrodinâmico tendem a ter uma orientação padrão, cujo seu sentido indica a direção deste agente (Kidwell et al., 1986). Segundo Nagle (1967), os eixos de maior comprimento dos bioclastos tendem a se orientar perpendiculares à direção das cristas das ondas incidentes na zona de espraiamento, e paralelos as cristas na zona de quebra e empolamento. Contrariando estas observações, o modelo físico apresentou um comportamento polimodal (sem orientação preferencial) para as orientações do eixo de maior comprimento dos gastrópodes na zona de domínio do espraiamento (depósito SA - Fig. 7A). Já as orientações dos bivalves e gastrópodes medidas na zona de quebra e empolamento (Fig. 7B), evidenciaram um paralelismo entre os eixos de maior comprimento das conchas e a direção das cristas de ondas, o que corrobora com os resultados de Nagle (1967).
Corroborando com Nagle (1967), o comportamento observado na zona de quebra e empolamento do modelo físico, tanto para os bivalves (eixo de maior comprimento a $90^{\circ}$ da direção do umbo) quanto para os gastrópodes de roseta bimodal (Fig. 7B), foi paralelo as cristas de onda (direção E-W). Em contrapartida, o comportamento polimodal das orientações do eixo de maior comprimento dos gastrópodes na zona de domínio do espraiamento (depósito SA Fig. 7A) não concordou com o definido por Nagle (1967).

Quanto ao posicionamento da concavidade dos bivalves, há uma forte tendência de concavidade para baixo em todos os tipos de concentração analisados (Fig. 7B, 7C e 7D), o que é esperado para conchas submetidas a algum fluxo trativo de corrente ou onda, pois denota uma posição hidrodinamicamente mais estável (Nagle, 1967; Brenchley \& Newall, 1970; Allen, 1984; Oliveira \& Wood, 1997; Simões \& Kowalewski, 1998; Fürsich \& Pandey, 1999; Silva, 2016; Porto-Barros et al., 2017). No entanto, este comportamento não seria esperado no

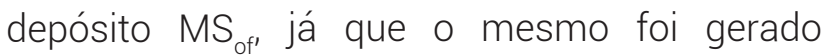
pelo bypass dinâmico de baixa intensidade energética e teve um percentual similar ao depósito $\mathrm{MS}_{\text {sh' }}$ que por sua vez foi gerado pelo retrabalhamento mecânico de alta energia. Ainda, o maior percentual de concavidade para baixo da concentração GS em relação à MS $_{\text {sh }}$ também contradiz as expectativas, já que GS foi gerado 
pela dinâmica de winnowing de intensidade energética intermediária (Fick et al., 2018). Em relação as tafofácies de Chinelatto et al. (2018), que mostram uma tendência de maior percentual de concavidade para baixo nas tafofácies mais proximais - T1, T2 e T3 - do que nas distais T4, T5 e T6 - (Tabela 2), no modelo físico não apresentaram uma correlação satisfatória quanto ao comportamento deste parâmetro, já que o maior percentual foi apresentado pelo depósito intermediário GS.

O grau de empacotamento e a proporção em peso entre matriz e bioclastos apresentaram uma boa correlação ao longo do perfil simulado (Fig. 10). Os depósitos $\mathrm{MS}_{\text {sh }}$ e $\mathrm{MS}_{\text {of }}$ cujas amostras rígidas tiveram empacotamento moderado/ disperso foram os que apresentaram as maiores proporções dematriz,enquanto o depósito GScom empacotamento denso / moderado apresentou as maiores proporções de bioclastos. Estes resultados sugerem uma relação direta do grau de empacotamento com a taxa de R-sediment (taxa de sedimentação não bioclástica - sensu Kidwell, 1986) das suas zonas de ocorrência no modelo físico. $\mathrm{MS}_{\mathrm{sh}}$ e $\mathrm{MS}_{\text {of }}$ ocorreram em áreas de deposição de areia no perfil simulado, ou seja, com R-sediment positivo, marcadas pela formação do banco de tempestade e do lençol de offshore (Fig. 10), o que gerou concentrações com empacotamento moderado/disperso e maior proporção em peso de matriz arenosa. Por outro lado, a concentração GS ocorreu em área de erosão do perfil dominada pelo winnowing, ou seja, com R-sediment negativo, marcada pelo baixio entre o banco de tempestade e o lençol de offshore gerando empacotamento denso e maior proporção de bioclastos (Fig. 10), o que corrobora com os apontamentos de Kidwell \& Holland (1991). Neste sentido, pode-se projetar que na concavidade da shoreface, outro setor do perfil que teve erosão durante as simulações, também é uma zona propícia a formar concentrações com denso empacotamento (matriz-suportada). Desde que haja um maior transporte de conchas provenientes de seu habitat mais distal (offshore), o que não ocorreu nos experimentos de Fick et al. (2018), depósitos com mais alto conteúdo de bioclastos tendem a se formar neste setor.

Analisando o comportamento dos parâmetros tafonômicos de uma maneira continua ao longo do perfil simulado (Fig. 10), principalmente a orientação topo-base, o empacotamento e a proporção em peso de matriz e bioclastos, constata-se que certos tipos de concentrações de conchas definidos por Fick et al. (2018) não possuem limites abruptos, e sim lateralmente transicionais. Isto é bastante visível principalmente entre os depósitos GS e $\mathrm{MS}_{\text {of, }}$ na qual o empacotamento da amostra rígida mais distal de GS (AR-5) varia de denso a moderado e o conteúdo de matriz já se mostra igual ao de bioclastos (Al-6). Ou seja, neste local este tipo de concentração vai apresentando características semelhantes a MS $_{\text {of }}$ : de empacotamento moderado e maior proporção de matriz em relação a bioclastos. Corroborando, a orientação topo-base da amostra AR-5 de GS também apresentou percentuais de conchas oblíquas e verticais semelhantes a amostra AR- 6 de $M_{\text {of }}$. Por outro lado, o comportamento dos referidos parâmetros tafonômicos sugerem limites mais abruptos entre $\mathrm{MS}_{\mathrm{sh}}$ / GS, especialmente pelos seu empacotamento e proporção de matriz e bioclastos, na qual passam, respectivamente, de moderado a denso e de $66 \%$ a $31 \%$ de matriz nas suas amostras limítrofes. Estes limites dos depósitos indicam estar associados ao processo de transformação de onda que controlam suas respectivas dinâmicas de acumulação. O limite abrupto entre $\mathrm{MS}_{\text {sh }}$ e GS sugere estar diretamente relacionado com o ponto de colapso das ondas de tempestade ( $1^{\circ}$ ponto de quebra), separando restritamente os processos de quebra e empolamento, ou seja, dois processos distintos que promovem dinâmicas diferentes, o retrabalhamento mecânico e o winnowing. Já o limite transicional de GS e $\mathrm{MS}_{\text {of }}$ se explica pelo fato que ambas as dinâmicas de concentração, winnowing e bypass dinâmico, foram controladas pelo empolamento e que um gradiente interno de energia, relacionado a maior deformação da onda a medida que se aproxima do banco de tempestade, possa as ter diferenciado gradualmente. 


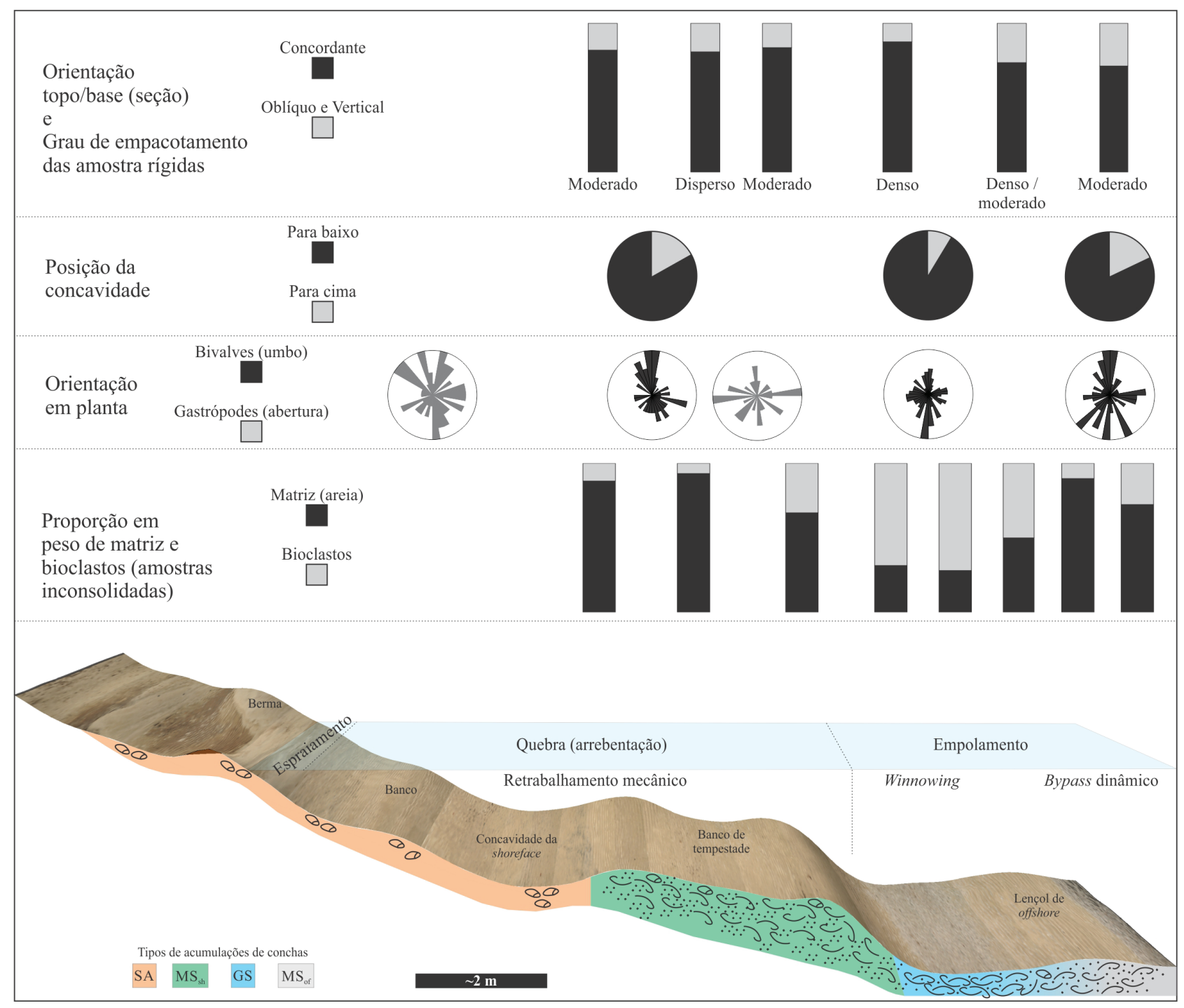

Figura 10. Compilação dos dados da análise tafonômica integrados ao modelo 3D do perfil costeiro simulado, no qual estão delimitadas as dinâmicas sedimentológicas de acumulação de bioclastos e os respectivos tipos de depósito gerados na modelagem física.

Figure 10. Data compilation from the taphonomic analysis integrated to the 3D model of the simulated coastal profile, where are delimited the sedimentological dynamics of bioclast accumulation and the deposit types generated in the physical modeling.

\section{Conclusões}

A análise tafonômica nos tipos de concentrações de conchas geradas no modelo físico de Fick et al. (2018) revela aspectos que reforçam as comparações com depósitos de coquinas do registro sedimentar. 0 comportamento das orientações topo-base e em planta ao longo do perfil foram os parâmetros que se mostraram mais semelhantes aos modelos padrões da literatura. Há tendência de um maior percentual de conchas concordantes em zonas proximais, onde domina a maior ação de ondas, e maior percentual de oblíquas e verticais em zonas distais (em posição de vida) onde domina a dinâmica de bypass dinâmico (menor ação de ondas). Jáas orientações em planta dos moluscos mostram comportamentos padrões bem definidos. Unimodais e bimodais (indicam a ação efetiva de um agente hidrodinâmico) e com eixo maior paralelo às cristas das ondas incidentes, nos setores de domínio do retrabalhamento mecânico (restrito a zona de quebra das ondas) e winnowing. Polimodais, sem padrão definido que indiquem ação de fluxos, marcaram a zona de domínio do bypass dinâmico. No entanto, o caráter polimodal dos gastrópodes na zona de espraiamento não concorda com o padrão bimodal e de eixo maior perpendicular a direção das cristas de onda esperados para este setor costeiro.

Os resultados da análise tafonômica 
permitiram identificar mais detalhadamente as características dos limites entre as concentrações de conchas, como mostraram os parâmetros orientação topo-base, empacotamento e proporção em peso de matriz e bioclastos. Os valores destes parâmetros evidenciaram um limite mais abrupto (alto contraste de valores) entre os depósitos $\mathrm{MS}_{\text {sh }}$ e GS, que foram governados por dois diferentes processos ondulatórios: quebra e empolamento; e transicional (valores variam gradualmente) para os depósitos GS e $\mathrm{MS}_{\text {of }}$ que foram controlados pelo mesmo processo de empolamento.

O imageamento aéreo e o levantamento topográfico do perfil costeiro simulado, apresentados neste trabalho, permitiram uma melhor visualização da morfologia do mesmo e associar as certas feições características aos tipos de concentrações de conchas vistos nas imagens de superfície. O banco de tempestade, o baixio adjacente e o lençol de offshore correspondem, respectivamente, aos depósitos $\mathrm{MS}_{\mathrm{sh}^{\prime}}$ GS e $\mathrm{MS}_{\text {of }}$.

Agradecimentos. Agradecemos ao aluno de Engenharia de Minas, Leonardo Pereira Machado, bolsista de iniciação científica que auxiliou diretamente na análise das amostras rígidas. Aos revisores Prof. Fernando Erthal e Prof. Matias Ritter pela importante contribuição ao melhoramento do manuscrito. Além disso, o primeiro autor gostaria de agradecer ao Conselho Nacional de Desenvolvimento Científico e Tecnológico (CNPq) do governo brasileiro pelo apoio financeiro.

\section{Referências}

Abrahão, D. \& Warme, J.E. 1990. Lacustrine and associed deposits in a rifted continental margin - Lower Cretaceous Lagoa Feia Formation, Campos Basin, offshore Brazil. In: Katz, B.J. (Ed.). Lacustrine Basin Exploration: Case Studies and Modern Analogs. American Association of Petroleum Geologists, Memoir 50, p. 287-305.

Allen, J.R.L. 1984. Experiments on the settling, overtuning and entrainment of bivalve shells and related models. Sedimentology, 31: 227-
250.

Bertani, R.T. \& Carozzi, A.V. 1985. Lagoa Feia Formation (Lower Cretaceous), Campos Basin, offshore Brazil: Rift Valley Stage lacustrine carbonate reservoirs - (I). Journal of Petroleum Geology, 8(1): 37-58.

Brenchley, P.J. \& Newall, G. 1970. Flume experiments on the orientation and transport of models and shell valves. Palaeogeography, Palaeoclimatology and Palaeoecology, 7: 185220

Carvalho, M.D., Praça, U.M., Silva-Telles, Jahnert, R.J., A.C. \& Dias, J.L. 2000. Bioclastic carbonate lacustrine facies models in the Campos Basin (Lower Cretaceous), Brazil. American Association of Petroleum Geologists, Studies in Geology, 46: 245-256.

Chinelatto, G.F., Vidal, A.C., Kuroda, M.C. \& Basilici, G. 2018. A taphofacies model for coquina sedimentation in lakes (Lower Cretaceous, Morro do Chaves Formation, NE Brazil). Cretaceous Research, 85: 1-19.

Dias, J.L., Oliveira, J.Q. \& Vieira, J.C. 1988. Sedimentological and stratigraphyc analysis of the Lagoa Feia Formation, Rift Phase of Campos Basin, offshore Brazil. Revista Brasileira de Geociências, 18(3): 252-260.

Erthal, F. \& Ritter, M.N. 2020. Taphonomy of Recent Bioclastic Deposits from the Southern Brazil Shelf: Stratigraphic Potential. In: Martínez S., Rojas A., Cabrera F. (Eds). Actualistic Taphonomy in South America. Topics in Geobiology, vol. 48. Cham, Springer, 1-20.

Fick, C., Borges, A.L.O. \& Manica, R. 2017. Sedimentologia e estratigrafia de um depósito deltaico gerado por modelagem física empregando amostragem tipo testemunho. Pesquisas em Geociências, 44(1): 79-91.

Fick, C., Toldo Jr., E.E \& Puhl, E. 2018. Shell concentration dynamics driven by wave motion in flume experiments: Insights for coquina facies from lake-margin settings. Sedimentary Geology, 374: 98-114.

Fornari, M., Giannini, P.C.F. \& Nascimento, D.R. 2012. Facies associations and controls on the evolution from a coastal bay to a lagoon system, Santa Catarina Coast, Brazil. Marine Geology, 323-325: 56-68.

Fürsish, F.T. \& Oschmann, W. 1993. Storm shell 
beds as tools in basin analysis: the Jurassic of Kachchh, western India. Journal of Geologic Society of London, 150: 169-185.

Fürsich, F.T. \& Pandey, D.K. 1999. Genesis and environmental significance of Upper Cretaceous shell concentrations from the Cauvery Basin, southern India. Palaeogeography,

Palaeoecology, 145: 119-139.

Futterer, E. 1982. Experiments on the distinction of wave and current influenced shell accumulations. In: Einsele, G. \& Seilacher, A. (Ed.). Ciclic and Event Stratification. Berlin, Springer-Verlag, p. 175-179.

Kidwell, S.M. 1986. Models for fossil concentrations: paleobiologic implications. Paleobiology, 12(1): 6-24.

Kidwell, S.M. 1991. The stratigraphy of shell concentrations. In: Allison, P.A. \& Briggs, D.E.G. (Ed.). Taphonomy, Releasing the Data Locked in the Fossil Record. New York, Plenum Press, p. 211-290.

Kidwell, S.M. \& Holland, S.M. 1991. Field description of coarse bioclastic fabrics. PALAIOS, 6(4): 426-434.

Kidwell, S.M., Fürsich, F.T. \& Aigner, T. 1986. Conceptual framework for the analysis and classification of fossil concentration. PALAIOS, 1: 228-238.

Muniz, M.C. 2013. Tectono-Stratigraphic evolution of the Barremian-Aptian Continental Rift Carbonates in southern Campos Basin, Brazil. Londres, 301p. Thesis of Doctoral, Faculty of SciencelEarth Sciences, Royal Holloway University of London.

Nagle, J.S. 1967. Wave and current orientation of shells. Journal of Sedimentary Petrology, 37(4): 1124-1138.

Oliveira, A.M. \& Wood, W.L. 1997. Hydrodynamics of bivalve shell entrainement. Journal of Sedimentary Research, 67(A): 514-526.

Porto-Barros, J.P., Dal'Bó, P.F., Fernandes, A.C.S. \& Borghi, L. 2017. Caracterização sedimentary e tafômica de depósitos bioclásticos na Reserva Tauá e Marina Búzios (Holoceno do Estado do Rio de Janeiro). Anuário do Instituto de Geociências - UFRJ, 40(2): 220-233.
Ritter, M.N., Erthal, F. \& Coimbra, J.C. 2013. Taphonomic signatures in molluscan fossil assemblages from the Holocene lagoon system in the northern part of the coastal plain, Rio Grande do Sul State, Brazil. Quaternary International, 305: 5-14.

Schäfer, W. 1972. Ecology and Paleoecology of Marine Environments. Chicago, The University of Chicago Press, 568 p.

Silva, F.R.S. 2016. Mobilização e transporte de conchas bivalves sob ação de correntes. Porto Alegre, 79p. Monografia de Conclusão de Curso, Curso de Geologia, Instituto de Geociências, Universidade Federal do Rio Grande do Sul.

Simões, M.G. \& Kowalewski, M. 1998. Shell beds as paleoecological puzzles: a case study from the Upper Permian of the Paraná Basin, Brazil. Facies, 38: 175-196.

Tavares, A.C., Borghi, L., Corbett, P., Nobre-Lopes, J. \& Câmara, R. 2015. Facies and depositional environments for the coquinas of the Morro do Chaves Formation, Sergipe-Alagoas Basin, defined by taphonomic and compositional criteria. Brazilian Journal of Geology, 45(3): 415-429.

Terra, G.J.S., Spadini, A.R., França, A.B., Sombra, C.L., Zambonato, E.E, Juschaks, L.C.S., Arienti, L.M., Erthal, M.M., Blauth, M., Franco, M.P., Matsuda, N.S., Silva, N.G.C., Moreti-Junior, P.A., D'Avila, R.S.F., Souza, R.S., Tonietto, S.N., Anjos, S.M.C., Campinho, V.S. \& Winter, W.R. 2010. Classificação das rochas carbonáticas aplicável às bacias sedimentares brasileiras. Boletim de Geociências da Petrobras, 18(1): 9-29.

Thompson, D.L., Stilwell, J.D. \& Hall, M. 2015. Lacustrine carbonate reservoirs from Early Cretaceous rift lakes of Western Gondwana: Pre-Salt coquinas of Brazil and West Africa. Gondwana Research, 28: 26-51.

Zuschin, M., Stachowitsch, M. \& Stanton, R.J. 2003. Patterns and processes of shell fragmentation in modern and ancient marine environments. Earth-Science Reviews, 63: 3382. 